\title{
Dental Plaque Streptococci and Their Amoxicillin Resistance in Children with Congenital Heart Anomalies: Results of a Prospective Study
}

\author{
Aida Rexhepi ${ }^{1}$, Raimonda Niko², Agim Begzati ${ }^{1}$, Mergime Prekazi Loxha ${ }^{3 *}$, Vjosa Krasniqi ${ }^{4}$, \\ Zana Agani ${ }^{4}$, Blerta Xhemajli' ${ }^{1}$, Teuta Kutllovci' ${ }^{1}$, Urata Tahiri ${ }^{1}$ \\ ${ }^{1}$ Department of Pediatric Dentistry, Clinical University Center of Kosova, Prishtina, Kosova \\ ${ }^{2}$ Pediatric Clinic, Faculty of Medicine, University of Tirana, Tirana, Albania \\ ${ }^{3}$ Department of Maxillofacial Surgery, Clinical University Center of Kosova, Prishtina, Kosova \\ ${ }^{4}$ Department of Oral Surgery, Clinical University Center of Kosova, Prishtina, Kosova \\ Email: ${ }^{*}$ mergimeloxha@gmail.com
}

Received 23 May 2014; revised 5 July 2014; accepted 20 July 2014

Copyright (C) 2014 by authors and Scientific Research Publishing Inc.

This work is licensed under the Creative Commons Attribution International License (CC BY). http://creativecommons.org/licenses/by/4.0/

c) (i) Open Access

\section{Abstract}

Children with congenital heart diseases (CHD) are considered to be at higher risk of development of a Bacterial Endocarditic (BE) from infectious diseases of the oral cavity and following dental treatments. They represent the largest group of patients with special medical needs who appear in the daily dental practice. Maintenance of oral health and oral hygiene is suitable to reduce the incidence of bacteremia. Oral hygiene is more important in reducing the risk of $B E$ than the administration of antibiotic-prophylaxis before dental procedures. The purpose of this study was to identify the strains of streptococci viridians group from dental plaque and their amoxicillin resistance at children with congenital heart disease. The study was carried out in University Dentistry Clinical Center of Kosova, Department of Pediatric Dentistry in cooperation with the Microbiologic Department. Participants in this study $(n=90)$ were children between 6 - 15 years old, divided in the control group of healthy children $(n=30)$, and two study groups, first group, children with CHD who have not taken antibiotics within last three months $(n=30)$ and second group, children with CHD who have taken antibiotics within three months $(n=30)$. The gram positive cocci were identified using the automated system, VITEK 2 (BioMerux), while for determining amoxicillin resistance cocci the disc diffusion method was used. By analyzing the three groups of children regarding isolated dental plaque streptococci, in general the Viridans group of streptococci (VGS) has dominated our results, with a higher percentage of streptococcus Mitis group

\footnotetext{
${ }^{*}$ Corresponding author.
} 
(37.2\%). The highest resistance of VGS against amoxicilin was in the group of children with CHD, which have been using antibiotics within 3 months $(23.3 \%)$. In the other two groups the resistance against amoxicillin was found in a lower percentage (3.3\%). Based on the results of our study we can conclude that frequent use of amoxicillin may result in an increasing antimicrobial resistance of streptococci.

\title{
Keywords
}

\author{
Congenital Heart Anomalies, Bacterial Endocarditis, Dental Bacterial Plaque, Bakteremia, \\ Streptococci, Antibiotics
}

\section{Introduction}

Oral health has an important role in general health, especially in children with congenital heart disease (CHD), who are considered to be at higher risk of development of a Bacterial Endocarditic (BE) from infectious diseases of the oral cavity and following dental treatments. They represent the largest group of patients with special medical needs who appear in the daily dental practice [1]. The initial factor for development of BE is bacteremia which can be caused by bacteria passing from the oral cavity [2]. Therefore, antibiotic prophylaxis before dental treatments is recommended for these patients. According to American Heart Association (AHA) guidelines published in 1997, patients with CHD are classified in three groups based on the risk to acquire BE as follows [3]-[5]:

High-risk category: Prosthetic cardiac valves, previous bacterial endocarditis, complex cyanotic heart disease (transposition of the great arteries, tetralogy of Fallot), and constructed systemic pulmonary shunts or conduits.

Moderate-risk category: Ventricular septal defect without surgical correction (VSD), Ductus Botalli, coarctation of aorta, pulmonary valve stenosis, aortic valve stenosis, mitral valve prolapse with valvular regurgitation.

Low-risk category: Isolated atrial septal defect (ASD), surgical repair of VSD, ASD and Ductus Botalli without residua beyond 6 months, mitral valve prolapsed without valvular regurgitation.

Dental procedures, prophylaxis recommended by AHA (1997) are: Dental extractions, periodontal surgery procedures, scaling, root canal treatment beyond the apex, intraligamentary local anesthetic injections, sub gingival placement of strips and initial placement of orthodontic bends but not brackets.

The new AHA guidelines for endocarditis prophylaxis were published in 2007 according to which antibiotic prophylaxis is recommended for dental procedures that involve manipulation of the gingival tissues or periapical tissue of teeth and perforation of the oral mucosa in patients presenting high risk factors [6]. The AHA recommendations for preventive antimicrobial administration against $\mathrm{BE}$ are based on the causative microorganisms. Approximately $80 \%$ of cases of BE are due to the gram-positive cocci, streptococci and staphylococci [7] [8]. The antibiotic most frequently described before dental treatment is amoxicillin in a dosage of $50 \mathrm{mg} / \mathrm{kg} 1$ hour before treatment for children or $2 \mathrm{~g}$ for adults.

In numerous recent studies antibiotic prophylaxis was considered a controversial issue, based on the fact that bacteremia can be caused spontaneously even in the absence of dentistry treatment, from routine daily activities in patients with poor oral hygiene. Recent studies suggest that amoxicillin therapy has a statistically significant impact on reducing the incidence, nature and duration of bacteremia from dental treatment, but it does not eliminate bacteremia [9] [10].

Maintenance of oral health and oral hygiene can reduce the incident of bacteremia from daily activities. Oral hygiene is more important in reducing the risk of $\mathrm{BE}$ than the administration of antibiotic-prophylaxis before dental procedures.

The risk of antibiotic-related possible negative effects exceeds the benefit of prophylactic therapy. One of the negative effects from frequent intake is the increase of resistant bacterial strains [11] [12].

The oral cavity contains the greatest variation of micro flora in the human body. The VGS represent the biggest population of oral bacteria and they are the main components of dental plaque (DP) [13]. Dental plaque streptococci are not only the main causes for oral pathologies, but also for BE. They are a heterogeneous group 
of organisms and are classified into 6 major groups: st.mitis group, st.salivarius group, st.mutans group, st.sanguinis group, st.anginosus group and st.bovis group [14]. The VGS are bacteria with a low virulence and are isolated from dental plaque, sputum, root canal, carious lesion, periodontal tissue and radix of extracted teeth, therefore the transient bacteremia can be caused from many oral procedures particularly on individuals with poor oral hygiene [15]. The odontogenic bacteremias are transient in nature and in healthy individuals the bacteria are eliminated from the bloodstream quickly by the immunity system. In patients with CHD, when there is tissue trauma from dental procedures, the bacteria can pass into the systemic circulation and settle, near or in the defect due to a slower blood-circulation [2]. Glucan, a metabolic product of streptococci, helps bacteria to attach to a cardiac valve defect in the same way as in dental enamel [16].

\section{Purpose of Study}

Due to the high number of patients with CHD in our Department, the purpose of this study was:

1) Identify the strains of VGS from dental plaque at children with CHD;

2) Determine the incidence of amoxicillin resistance of VGS in children with CHD who have taken antibiotics within the last three months;

3) Identify the amoxicillin-resistant bacterial strains.

\section{Materials and Methods}

Participants in this study $(\mathrm{n}=90)$ were children of an age between 6 and 15 yrs. The entire group was divided into the control group of healthy children $(n=30)$ and two study groups: the first study group were children with CHD who have not taken antibiotics within last three months $(n=30)$ and the second study group were children with CHD who have take antibiotics within three months $(n=30)$. The general anamnesis was taken from the parents of the children. Additionally the anamnesis data that were of special interest for this study—such as the type of anomaly, previous use and the type of antibiotic - were collected. The study was carried out in the University Dentistry Clinical Center of Kosova, Department of Pediatric Dentistry in cooperation with the Microbiologic Department.

\section{Microbiological method}

The gram positive cocci were identified using the automated system, VITEK 2 (BioMerieux) and colorimetric GP card for the identification of gram-positive cocci. After 6 - 8 hours incubation, reactions were read automatically.

The samples were obtained from the dental plaque of the buccal surfaces of the first (deciduous or permanent) molars of the lower jaw and incisors (deciduous or permanent) of the upper jaw using the sterile swab sticks and were sent for microbiological analysis. The samples taken from dental plaque (DP) were firstly diluted in physiological saline $0.9 \%$ and then placed on nutrient or blood agar plate. The nutrient agar plate for bacterial cultivation was placed in the microbiological incubator for 24 hours in temperature of $37^{\circ} \mathrm{C}$. After the bacterial cultivation the material was taken from nutrient agar plate and placed in to the special beaker for creation of the bacterial suspension. Suspension was done by the mixed material with the saline $0.9 \%$ in the amount of $2-3 \mathrm{ml}$. The suspension beakers were connected through a special tube with GP card. Through this tube the material from the beaker is transferred to GP card and then the set of cards placed in apparatus of Vitek for identification of bacterial strains. For determining of amoxicillin resistance cocci was used the disc diffusion method.

\section{Results}

From the three investigated groups we have isolated at least two dominant bacterial strains from dental plaque. Between the groups there were not significant differences regarding bacterial strains $(P>0.05)$. In the healthy group of children, Streptococcus mitis was isolated in $63.3 \%$ of the cases, in the group of children with CHD, which have been using antibiotics within the last 3 months, in 70\% of the cases and in the group of children with CHD but without administration of antibiotics within the last 3 months in $73.3 \%$ of the cases. Streptococcus oralis was isolated as follows: $60 \%$ in the healthy group, $66.7 \%$ in the group with CHD with antibiotics and $70 \%$ in the group with CHD but without antibiotics (Table 1).

An amoxicillin-resistance of VGS was observed only in one patient from the healthy group (3.3\%), and in one patient from the group of children with CHD but without administration of antibiotics within the last 3 months 
(3.3\%), while in the group of children with CHD with antibiotic treatment within the last 3 months seven patients showed an amoxicillin-resistance (23.3\%) (Table 2).

In the dental plaque from all investigated children we have isolated strains of mitis group, (37.2\%), non viridans group of streptococci (8.6\%), strains of sanguinis group (7.8\%), strains of salivarius group (6.7\%), strains of anginosus group (3.3\%), strains of mutans group (2.8\%) and strains of bovis group (2.8\%) (Figure 1).

Amoxicillin high level resistance was observed for streptococcus sanguinis (20\%), then streptococcus oralis (13.6\%), streptococcus mitis (12.9\%) and streptococcus salivarius (11.1\%) (Figure 2).

Table 1. Occurrence of VGS strains from dental plaque.

\begin{tabular}{|c|c|c|c|c|c|c|}
\hline \multirow{2}{*}{ Group } & \multicolumn{2}{|c|}{ Healthy Gr. } & \multicolumn{2}{|c|}{ CHD with Ant. } & \multicolumn{2}{|c|}{ CHD without Ant. } \\
\hline & $\mathbf{N}$ & $\%$ & $\mathbf{N}$ & $\%$ & $\mathbf{N}$ & $\%$ \\
\hline Total & 30 & 100.0 & 30 & 100.0 & 30 & 100.0 \\
\hline Mitis & 19 & 63.3 & 21 & 70.0 & 22 & 73.3 \\
\hline Oralis & 18 & 60.0 & 20 & 66.7 & 21 & 70.0 \\
\hline Cristatus & 1 & 3.3 & 1 & 3.3 & 1 & 3.3 \\
\hline Pneumonie & 3 & 10.0 & 3 & 10.0 & 4 & 13.3 \\
\hline Anginosus & 2 & 6.7 & 2 & 6.7 & 1 & 3.3 \\
\hline Constelatus & 2 & 6.7 & - & - & 1 & 3.3 \\
\hline Intermedius & - & - & 1 & 3.3 & - & - \\
\hline Salivarius & 5 & 16.7 & 3 & 10.0 & 1 & 3.3 \\
\hline Thermophilus & 2 & 6.7 & 2 & 6.7 & - & - \\
\hline Vestibularis & 3 & 10.0 & 2 & 6.7 & - & - \\
\hline Mutans & 1 & 3.3 & 1 & 3.3 & 1 & 3.3 \\
\hline Sobrinus & 1 & 3.3 & 1 & 3.3 & - & - \\
\hline Sanguinis & 5 & 16.7 & 5 & 16.7 & 5 & 16.7 \\
\hline Parasanguinis & 1 & 3.3 & - & - & 1 & 3.3 \\
\hline Gordoni & 1 & 3.3 & 2 & 6.7 & 1 & 3.3 \\
\hline Galolyticus & 1 & 3.3 & 1 & 3.3 & - & - \\
\hline Alactolyticus & - & - & 2 & 6.7 & 1 & 3.3 \\
\hline
\end{tabular}

Table 2. Incidence rate of amoxicillin resistant VGS in children's groups Antimicrobial sensitivity: $\mathrm{I}$-inermediate, $\mathrm{R}$-resistance, $\mathrm{S}$ - sensitive.

\begin{tabular}{ccccccccc}
\hline \multirow{2}{*}{ Amoxicilin } & \multicolumn{2}{c}{ Healthy Gr. } & \multicolumn{2}{c}{ CHD Gr. with Ant. CHD Gr. without Ant. } & \multicolumn{2}{c}{ Total } \\
\cline { 2 - 8 } & No & $\%$ & No & $\%$ & No & $\%$ & No & $\%$ \\
\hline I & 1 & 3.3 & - & - & 2 & 6.7 & 3 & 3.3 \\
R & 1 & 3.3 & 7 & 23.3 & 1 & 3.3 & 9 & 10.0 \\
S & 28 & 93.3 & 23 & 76.7 & 27 & 90.0 & 78 & 86.7 \\
Total & $\mathbf{3 0}$ & $\mathbf{1 0 0 . 0}$ & $\mathbf{3 0}$ & $\mathbf{1 0 0 . 0}$ & $\mathbf{3 0}$ & $\mathbf{1 0 0 . 0}$ & $\mathbf{9 0}$ & $\mathbf{1 0 0 . 0}$ \\
\hline
\end{tabular}




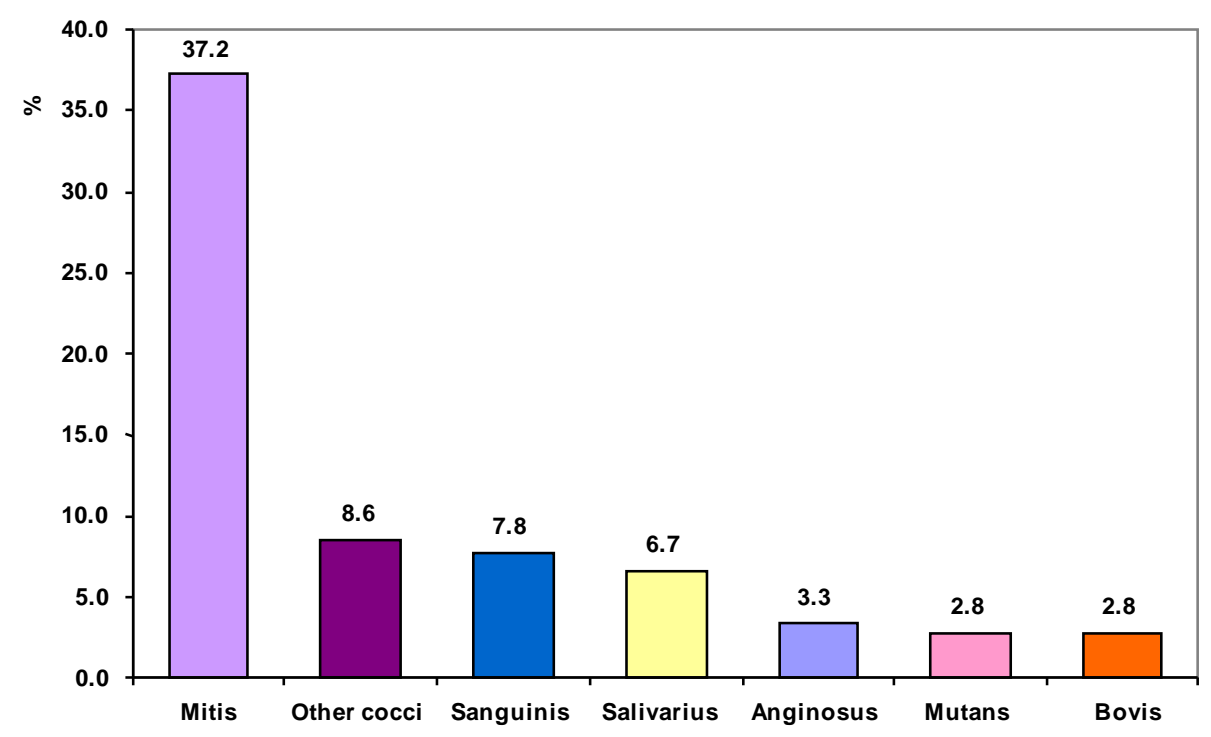

Figure 1. Prevalence of VGS and other cocci isolated from dental plaque.

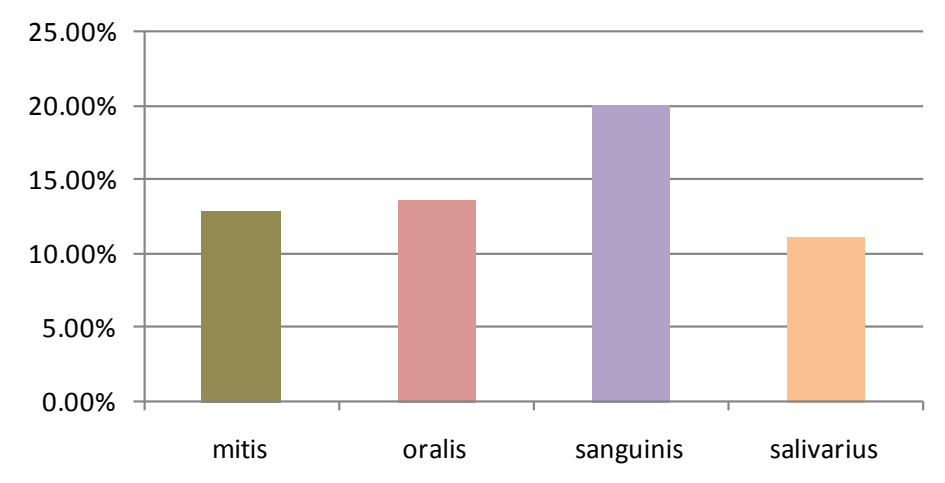

Figure 2. Prevalence of bacterial strains resistant in amoxicillin.

\section{Discussion}

The objective of this study was to investigate the identification of dominant strains among VGS which are part of microbial flora of dental plaque in children with CHD compared to healthy children. In addition, this study has researched the VGS resistance against amoxicillin, since an antibiotic prophylaxis against BE is required at CHD patients before dental treatment. The isolated dental plaque streptococci at the three groups of children were analysed and compared. The results revealed a domination of the Viridans group of streptococci, with a higher percentage of streptococcus mitis (37.2\%) followed by the Sanguinis group with 7.8\%, Salivarius with 6.7\%, Anginosus group with 3.3\%, Mutans and Bovis group both with $2.8 \%$.

The results of our study regarding the identification and the dominance of streptococci from DP correspond closely with the data published by other authors. The results published by Rozkeivicz D et al., suggest the prevalence of the DP-streptococci to be dominated by VGS in $72 \%$ of patients. St.mitis (27.3\%) is isolated at the highest rate followed by st.oralis (15.8\%), st.salivarius (9.7\%) st.sanguinis (8.3\%) st.vestibullaris (4\%) and st. mutans (1\%) [17].

According to results published by Smith et al. (2004) regarding the identification of bacterial species, from a total of 155 isolated VGS strains, frequently isolated organisms were st.oralis strains ( $n=67$ ), st.mitis strains ( $n$ $=66)$, st.sanguinis $(n=7)$, st.salivarius $(n=5)$, st.parasanguinis $(n=4)$, st.gordoni $(n=3)$ and st.mutans $(n=3)$ [18].

Our study has investigated the resistance of isolated streptococci from DP against amoxicillin and has reported a higher resistance of VGS strains in children with CHD which have been using antibiotics within the last 
3 months (23.3\% of cases). In the other two groups, consisting of children with CHD, which have not used antibiotics within the last 3 months period, and the healthy group, the resistance against amoxicillin was in a lower percentage (3.3\% of cases). Our findings regarding the resistance against amoxicillin between the groups are similar with the findings from author Koh.J et al. (1986), which have also obtained the supragingival plaque samples from children with CHD and healthy children. The results of their research report a higher level of resistance against amoxicillin for oral streptococci in children with CHD [19].

Conversely, Masuda K et al. (2012) investigated the resistance of the dental plaque streptococci against amoxicillin in healthy children. Among 120 patients investigated in this study, 5 patients resulted with resistance of VGS strains against amoxicillin. Furthermore, this study has shown the highest resistance for st.sanguinis, st.oralis and st.mitis [7].

The results of our study have confirmed the findings of similar studies published by other authors worldwide. According to our results, the resistance against amoxicillin from overall isolated of st.sanguinis strains was $20 \%$, for st.oralis strains $13,6 \%$, st.mitis strains $12.9 \%$ and for st.salivarius was $11.1 \%$. In comparison, Logman LP et al. (1991), investigated the antimicrobial resistance of dental plaque streptococci against amoxicillin and erythromicin in suspected patients for development of BE and in 65 patients they have isolated the amoxicillin and eritromicin resistant streptococci. Most resistant streptococci were strains of st.sanguinis, st.mitis and st.salviarius [20]. In a study about the prevalence rate and antibiotic susceptibility of VGS in healthy children population, Rozkiewics D et al. (2006), reports the resistance of isolated dental plaque streptococci against penicillin. Based on their research results, the highest resistance was for streptococcus mitis (30.5\%), followed by, st.oralis (19.1\%), st.salivarius (13.3\%) and st.sanguinis (8.8\%) [17]. Smith A. et al. (2004) reports significant differences in sensitivity against antibiotics for VGS strains with higher resistance for st.oralis (27\% against penicillin, 51\% against erythromycin and $6 \%$ against clindamicin) and for st.mitis (11\% against penicillin, $40 \%$ against erythromycin and $3 \%$ against clindamicin) [18].

\section{Conclusion}

Based on the results of our study we can conclude that the frequent use of amoxicillin may increase the antimicrobial resistance of streptococci. Due to the importance of oral health in development of bacterial endocarditis in children with CHD, it is healthier to encourage maintenance of oral hygiene and to apply prophylactic dentistry measures. The prophylactic measures are more crucial in reducing the risk of BE than the administration of antibiotic-prophylaxis prior to dental procedures, as per the specific requirements. If the patient with CHD has used amoxicillin during the previous three months, then prior to dental procedures we recommend the identification of bacterial sensitivity isolated from the dental plaque by disc diffusion in antibiotics according to AHArecommendation—amoxicillin, clindamicin, cephalexin and erythromycin.

\section{References}

[1] Cameron, A. and Widmer, R. (1997) Pediatric Dentistry, Mosby.

[2] Parahitiyawa, N.B., Jin, L.J., Leung, W.K., Yam, W.C. and Samaranayake, L.P. (2009) Microbiology of Odontogenic Bacteremia: beyond Endocarditis. Clinical Microbiology Reviews, 22, 46. http://dx.doi.org/10.1128/CMR.00028-08

[3] Dajani, A.S., Taubert, K.A., Wilson, W. and Bolger, A.F. (1997) Prevention of Bacterial Endocarditis: Recomandations by the American Heart Association. Circulation, 96, 358-366. http://dx.doi.org/10.1161/01.CIR.96.1.358

[4] Saymour, R.A., Lowry, R. and Whitworth, J.M. (2000) Infective Endocarditis, Dentistry and Antibiotic Prophylaxis; Time for a Rethink? British Dental Journal, 189, 610-616. http://dx.doi.org/10.1038/sj.bdj.4800845

[5] Reachel, B.S. and Farington, E. (2007) Prophylaxis for Bacterial Endocarditis Prior to Dental Procedures in Children. Journal of Pediatric Health Care, 21, 256-258.

[6] Willson, W., Taubert, C.A., Gewitz, M., Lockhart, P.B., et al. (2007) Prevention of Infective Endocarditis: Guidelines from the American Heart Association. Circulation, 116, 1736-1754.

[7] Masuda, K., Nemoto, H., Nakano, K., et al. (2012) Amoxicillin-Resistant Oral Streptococci Identified in Dental Plaque Specimens from Healthy Japanese Adults. Journal of Cardiology, 59, 285-290.

[8] Koh, J., Wilson, M. and Vidic, J. (1986) Amoxicilin-Resistant Streptococci in Dental Plaque. Microbios, 45, 41-53

[9] Lockhart, P.B., Brennan, M.T., Kent, M.L., Norton, H.J. and Weinrib, D.A. (2004) Impact of Amoxicillin Prophylaxis on the Incidence, Nature, and Duration of Bacteremia in Children after Intubation and Dental Procedures. Circulation, 109, 2878-2884. http://dx.doi.org/10.1161/01.CIR.0000129303.90488.29 
[10] Reachel, B.S. and Farington, E. (2007) Prophylaxis for Bacterial Endocarditis Prior to Dental Procedures in Children. Journal of Pediatric Health Care, 21, 256-258.

[11] Wilson, W., et al. (2007) AHA Guideline. Circulation, 116, 1736-1754. (Published online before print April 19, 2007) http://dx.doi.org/10.1161/CIRCULATIONAHA.106.183095

[12] Embil, J.M. and Chan, K.-L. (2008) The American Heart Association 2007 Endocarditis Prophylaxis Guidelines: A Compromise between Science and Common Scense. Canadian Journal of Cardiology, 24, 673-675. http://dx.doi.org/10.1016/S0828-282X(08)70664-0

[13] Damian, M., Palade, A.M., Băltoiu, M., Petrini, A., Păuna, M. and Roseanu, A. (2010) Phenotypic and Molecular Methods Used for Identification of Oral Streptococci and Related Microorganisms. Roumanian Archives of Microbiology and Immunology, 69, 85-89.

[14] Facklam, R. (2002) What Happened to the Streptococci: Overview of Taxonomic and Nomenclature Changes. Clinical Microbiology Reviews, 15, 613-630. http://dx.doi.org/10.1128/CMR.15.4.613-630.2002

[15] Wahl, M.J. and Pallasch, T.J. (2005) Dentistry and Endocarditis. Current Infectious Disease Reports, 7, 251-256.

[16] Larsen, T., Fiehn, N.E., Gutschik, E. and Bangsborg, J.M. (1999) Current Status of Taxonomic Groups of Oral Streptococci in Endocarditis. Can Virulence Factors Discriminate between Endocarditis and Non-Endocarditis Strains? Clinical Microbiology and Infection, 5, 73-77. http://dx.doi.org/10.1111/j.1469-0691.1999.tb00106.x

[17] Rozkiewicz, D., Daniluk, T., Sciepuk, M., Zremba, M.L., Milewska, R. and Stokowska, W. (2006) Prevalence Rate and Antibiotic Susceptibility of Oral Viridans Group Streptococci (VGS) in Healthy Children Population. Advances in Medical Sciences, 51, 191-195.

[18] Smith, A., Jackson, M.S. and Kennedy, H. (2004) Antimicrobial Susceptibility of Viridans Group Streptococcal Blood Isolates to Eight Antimicrobial Agents. Scandinavian Journal of Infectious Diseases, 36, 259-263. http://dx.doi.org/10.1080/00365540410019435

[19] Koh, J., Wilson, M. and Vidic, J. (1986) Amoxicilin-Resistant Streptococci in Dental Plaque. Microbios, 45, 41-53.

[20] Lesley, P., Logman, N., Patricia, K., et al. (1991) Antibiotic-Resistant Oral Streptococci in Dental Patients Susceptible to Infective Endocarditis. Journal of Medical Microbiology, 34, 33-37. http://dx.doi.org/10.1099/00222615-34-1-33 
Scientific Research Publishing (SCIRP) is one of the largest Open Access journal publishers. It is currently publishing more than 200 open access, online, peer-reviewed journals covering a wide range of academic disciplines. SCIRP serves the worldwide academic communities and contributes to the progress and application of science with its publication.

Other selected journals from SCIRP are listed as below. Submit your manuscript to us via either submit@scirp.org or Online Submission Portal.
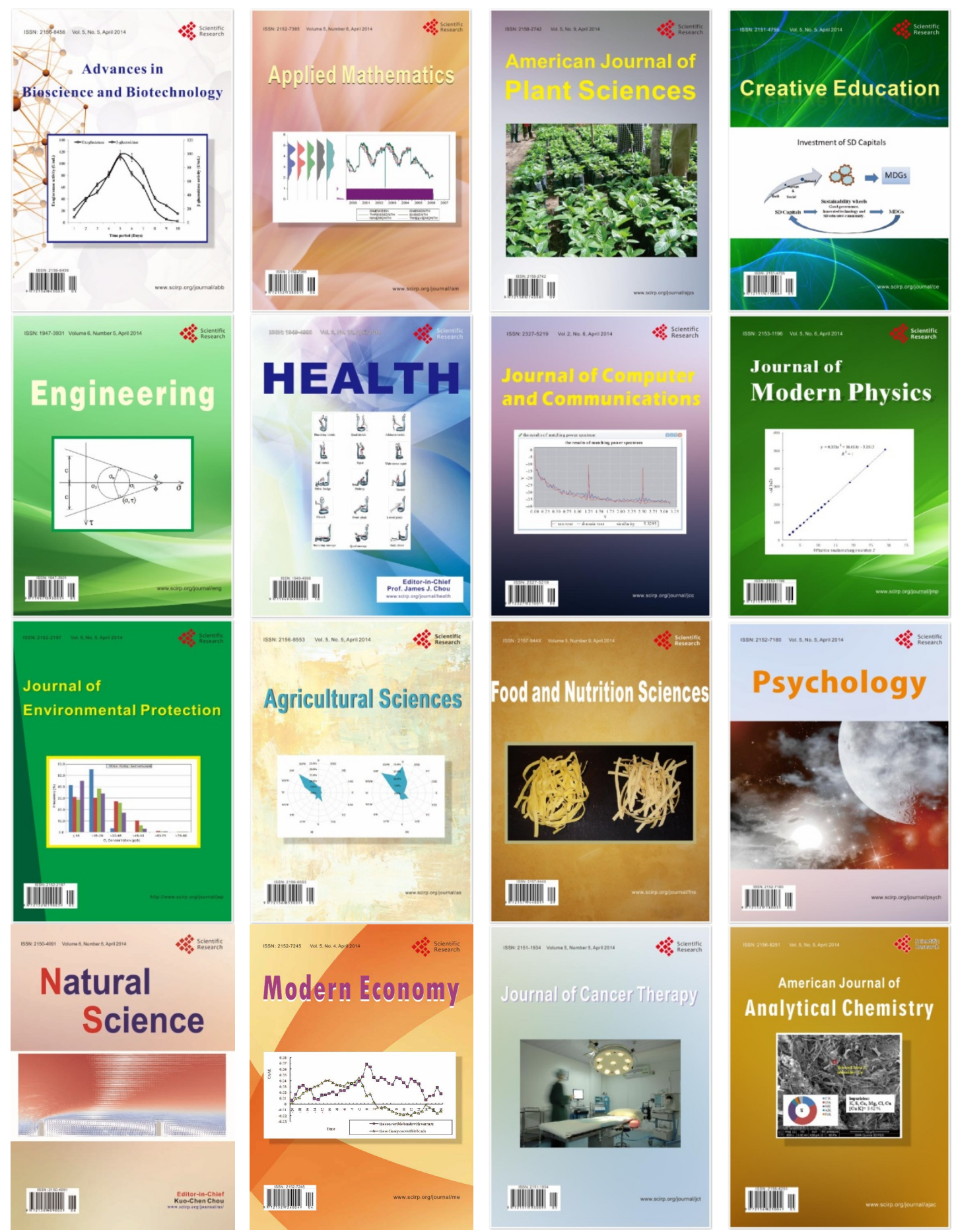